\title{
Shaken vs scraped: floral presentation contributes to pollinator guild segregation in co-blooming Symphionema montanum and Isopogon anemonifolius (Proteaceae)
}

\author{
P. Bernhardt ${ }^{1,2}$, G.R. Camilo ${ }^{1} \&$ P.H. Weston ${ }^{2}$ \\ ${ }^{1}$ Department of Biology, Saint Louis University, \\ 3507 Laclede Avenue, St Louis, MO 63103-2010 USA. \\ peter.bernhardt@slu.edu \\ ${ }^{2}$ National Herbarium of New South Wales, Royal Botanic Garden, \\ Mrs Macquaries Road,Sydney NSW 2000, Australia.
}

\begin{abstract}
Sympatric populations of Symphionema montanum R.Br. and Isopogon anemonifolius (Salisb.) Knight showed overlapping flowering periods during November 2009 in the Blue Mountains (New South Wales, Australia). Symphionema montanum has porose anthers encircling the protruding style, and lacks a pollen presenter. In contrast, sessile, longitudinally dehiscent anthers of Isopogon anemonifolius deposit pollen grains on the subterminus of the style (pollen presenter). Neither species secretes nectar. The majority of foragers on Symphionema montanum were polylectic, female bees (Halictidae). Their pollen foraging resembled sonication and shaking. Polylectic, female bees (Colletidae) were dominant foragers on Isopogon anemonifolius grasping styles with their mandibles while scraping the pollen presenter. Exoneura species (Apidae) visited both shrubs. Only two specimens of Callomelitta antipodes on Isopogon anemonifolius carried pollen of both shrub species. Most bees, collected on either shrub, carried the grains of their host mixed with one to six pollen morphotypes of co-blooming, nectariferous taxa. We report a positive correlation between an increase in bee size and the number of morphotypes carried but colletids of Isopogon anemonifolius carried fewer morphotypes than halictids on Symphionema montanum.
\end{abstract}

Keywords. Anther, bees, dehiscent, floral presentation, pollen load

\section{Introduction}

The Proteaceae is a family of woody plants with a southern distribution that is characterised by variation in inflorescence architecture and floral morphology. This includes a number of parallel evolutionary changes in different lineages including at least 15 transitions from radial to bilateral symmetry and at least two reversals to radial symmetry. These transitions reflect selective changes in modes of floral presentation ultimately changing mechanisms of pollen dispersal and pollen reception (Ye et al., 2012; Reyes et al., 2016; Citerne et al., 2017). Similarly, the number and morphology of nectar glands (Rao, 1971) and the presence or absence of a pollen presenter, a sub-terminal part of the style modified for pollen dispersal (sensu Johnson \& Briggs, 1975), have undergone multiple parallel and reversed transitions (Weston, 
2007, 2014). As speciation in certain angiosperm lineages is based, in large part, on divergence in pollination and breeding systems (e.g. Tremblay et al., 2004) variation in the presentation of inflorescences and flowers in the Proteaceae should reflect varying degrees of coadaptation with fluctuating pollinator guilds over time (Collins \& Rebelo, 1987).

In fact, different lineages in the Proteaceae have diverse, and often overlapping, pollination systems, depending on various animals (Collins \& Rebelo, 1987) or air currents (Welsford et al., 2016). Taxa known to be either bird- or mammal- or windpollinated, or having a floral morphology consistent with classic vertebrate or wind pollination syndromes, all nest within the current phylogeny of the family (Weston, 2007). This suggests that entomophily is probably ancestral with vertebrate and wind pollination arising independently in a number of lineages (Johnson \& Briggs, 1975). Vertebrate pollination evolved repeatedly in some of the larger genera (Johnson et al., 2012; Steenhuisen et al., 2012) and some modes of insect-pollination evolved secondarily from bird-pollinated ancestors (Mast et al., 2012). While vertebrate pollination in the Proteaceae of Australia and southern Africa has been studied intensively since the 1970 's, there are far fewer studies focussed on insect-pollinated taxa in this family. This may create the impression that the Proteaceae is predominantly or ancestrally vertebrate-pollinated (see Low, 2016). However, there are still no publications based on phylogenetically rigorous attempts to reconstruct the family's ancestral pollination system(s). This is due, primarily, to the absence of field studies on the pollination systems of the phylogenetically diverse, arborescent, rainforest taxa (Williams \& Adam, 2010).

Insect-pollination in the Proteaceae by members of anthophilous taxa in the orders Coleoptera, Diptera, Hymenoptera and Lepidoptera has been documented repeatedly in the flora of southern Africa (Collins \& Rebelo, 1987; Hattingh \& Giliomee, 1989; Johnson et al., 2012; Steenhuisen et al., 2012). In Australia, though, some insect visitors to flowers of the Proteaceae are regarded as either disruptive or inefficient pollen vectors compared to native birds (Ramsey, 1988; Vaughton, 1996). Nevertheless, the flowers of many Australian species are so small that they are most likely pollinated by insects. Houston (1989) proposed pollination by a specialised lineage of bees within the genus Leioproctus (Colletidae) when they visit the flowers of Conospermum Sm. species in Western Australia. Hawkeswood (2007) showed jewel beetle-pollination (Buprestidae) in eastern Conospermum taxifolium C.F.Gaertn. Persoonia Sm. species in eastern Australia depend primarily on bees in the genus Leioproctus, with some additional pollen dispersal from bees in the families Halictidae and Megachilidae (Bernhardt \& Weston, 1996). The commercially important species in the genus Macadamia F.Muell. are pollinated by a combination of native and introduced eusocial bees in the family Apidae (Vithanage \& Ironside, 1986; Heard, 1994). Therefore, insect-pollination in the Proteaceae of Australia is probably far more common than anticipated and should be documented with more field studies instead of classifying flowers on the bases of syndrome characters (e.g. Faegri \& Van der Pijl, 1979). 
The genera Symphionema R.Br. and Isopogon R.Br. ex Knight are of particular interest for three interrelated reasons. First, morphological studies of species in both lineages show that neither contains floral nectaries (Rao, 1971) as confirmed by Harden (2002a, 2002b) and Telford (1995). Second, although the flowers of both species are more or less actinomorphic, the two species have strikingly different modes of floral presentation. Symphionema montanum produces flowers on slender spikes that open acropetally and sub-synchronously, while Isopogon anemonifolius produces inflorescences in compact globular heads where individual flowers also develop acropetally (see photos in Blomberry \& Maloney, 1992). The flowers of these two species also differ in patterns of floral pigmentation. Their modes of pollen presentation diverge significantly. Flowers of Symphionema montanum have stamens adnate to their tepals only at their bases. Their anthers tightly encircle the protruding style, which lacks a pollen presenter (Johnson \& Briggs, 1975). In contrast, flowers of Isopogon anemonifolius bear very short staminal filaments adnate to the tepals well above their bases. Their almost sessile anthers dehisce in the bud, depositing pollen grains on the subterminal portion of the style, which serves as a pollen presenter. Following anthesis, these tepals and their adnate anthers, reflex, exposing the prominently protruding style. Third, Isopogon anemonifolius and Symphionema montanum have overlapping distributions and flowering periods in the Blue Mountains of New South Wales.

Interestingly, Carolin (1961) interpreted anther biomechanics in Symphionema as explosive. Does this mean that both species share the same pollinators that forage regularly on flowers that lack nectar or does each species attract a different spectrum of pollination vectors due to different modes of floral presentation? Furthermore, is pollinator diversity and vector fidelity influenced by co-blooming species that do secrete nectar providing chemical energy to insects that forage on the flowers of species that are pollen-rich but nectar-absent (see Bernhardt, 1984, 1986, 1987, 1989, 1995, 1996; Bernhardt \& Montalvo, 1979)?

\section{Materials and methods}

Study sites and collection dates

Our field sites are characterised below and the dates on which we conducted our observations are listed. Associated plant species noted in bloom are indicated by (fl). Specimens of Isopogon anemonifolius and Symphionema montanum were collected at each site and vouchers are deposited at the National Herbarium of New South Wales, Sydney (NSW).

Site 1: Within $0.05 \mathrm{~km}$ of the Blue Mountains Heritage Centre, Blackheath, New South Wales, Australia, 33³7'50"S, 150¹8'24"E $\pm 50 \mathrm{~m}$ (datum: AGD66), altitude $1020 \mathrm{~m} \pm 10 \mathrm{~m}$. Topography: Gentle slope $<5^{\circ}$. Soil and substrate: yellow-brown stony sand derived from Narrabeen Sandstone. Dry sclerophyll forest dominated by Eucalyptus piperita Sm., E. sclerophylla (Blakely) L.A.S.Johnson \& Blaxell, E. sieberi L.A.S.Johnson (fl); shrubby understorey with Leptospermum trinervium (Sm.) Joy Thomps. (fl), Symphionema montanum (fl), Isopogon anemonifolius (fl), Lambertia 
formosa Sm. (fl), Banksia spinulosa Sm., Telopea speciosissima (Sm.) R.Br. (fl), Grevillea laurifolia Sieber ex Sprengel (fl), Persoonia levis (Cav.) Domin, Poranthera corymbosa Brongn. (fl), Sowerbaea juncea Andrews (fl), Diuris sulphurea R.Br. (fl), Dampiera stricta (Sm.) R.Br. (fl), Dampiera purpurea R.Br. (fl). Site visited $2 \& 10$ November 2009.

Site 2: Mt Wilson Road, $2.35 \mathrm{~km}$ NE of junction with Bells Line of Road, New South Wales, Australia, 333 $31^{\prime} 58^{\prime \prime S}, 150^{\circ} 20^{\prime} 57^{\prime \prime} \mathrm{E} \pm 20 \mathrm{~m}$ (datum: AGD66), altitude $930 \mathrm{~m} \pm 10 \mathrm{~m}$. Topography: slope just below ridge top. Soil and substrate: yellowbrown stony sand derived from Narrabeen Sandstone. Associated plant community: Dry sclerophyll forest dominated by Eucalyptus piperita, E. sclerophylla, E. sieberi (fl); shrubby understorey with Symphionema montanum (fl), Isopogon anemonifolius (fl), Persoonia chamaepitys A.Cunn. (fl), Leptospermum trinervium (fl), Lambertia formosa (fl), Banksia serrata L.f., Petrophile pulchella (Schrad. \& J.C.Wendl.) R.Br., Conospermum taxifolium (fl), Conospermum tenuifolium R.Br. (fl), Hakea laevipes Gand. (fl), Lomatia silaifolia (Sm.) R.Br., Mirbelia rubiifolia (Andrews) G.Don (fl), Tetratheca rupicola Joy Thomps. (fl), Patersonia sp. (fl), Sowerbaea juncea (fl), Thelymitra ixioides Sw. (fl), Thelymitra sp. aff. pauciflora $\mathrm{R}$.Br. (fl). Site visited 3 \& 9 November 2009.

Site 3: Hat Hill Road, $0.05 \mathrm{~km}$ ENE of junction with Twin Falls Road, Blackheath,

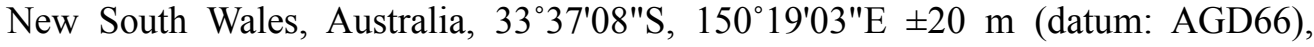
altitude $1020 \mathrm{~m} \pm 10 \mathrm{~m}$. Topography: Gently undulating plateau. Soil and substrate: yellow-brown stony sand derived from Narrabeen Sandstone. Dry sclerophyll forest dominated by Eucalyptus piperita, E. sclerophylla, E. sieberi (fl); shrubby understorey with Leptospermum trinervium (fl), Symphionema montanum (fl), Isopogon anemonifolius (fl), Banksia cunninghamii Sieber ex Rchb., Petrophile pulchella, Conospermum taxifolium (fl), Hakea dactyloides (Gaertn.) Cav. (fl), Hakea teretifolia (Salisb.) Britten subsp. teretifolia, Telopea speciosissima (fl), Persoonia mollis R.Br. subsp. mollis, Persoonia levis, Persoonia myrtilloides Sieber ex Schult. \& Schult.f. subsp. myrtilloides, Persoonia chamaepitys (fl), Daviesia ulicifolia Andrews subsp. ulicifolia, Dillwynia retorta (J.C.Wendl.) Druce complex (fl), Acacia obtusifolia A.Cunn., Acacia terminalis (Salisb.) J.F.Macbr., Polyscias sambucifolia (Sieber ex DC.) Harms, Pteridium esculentum (G.Forst.) Cockayne subsp. esculentum, Gleichenia sp., Poranthera corymbosa (fl), Patersonia sp. (fl), Sowerbaea juncea (fl). Site visited 5 \& 13 Nov 2009.

Site 4: Bells Line of Road, $1.45 \mathrm{~km} \mathrm{NW}$ of junction with Mt Wilson Road, New South Wales, Australia, 3332'20" S 150 19'32"E \pm 30 m (datum: AGD66), altitude $990 \mathrm{~m} \pm 10 \mathrm{~m}$. Topography: Ridge top. Soil and substrate: brown stony sand derived from Narrabeen Sandstone. Dry sclerophyll forest dominated by Eucalyptus piperita, E. sclerophylla; shrubby understorey with Leptospermum trinervium (fl), Isopogon anemonifolius (fl), Banksia serrata, Petrophile pulchella, Hakea dactyloides (fl), Persoonia levis, Daviesia ulicifolia subsp. ulicifolia, Phyllota squarrosa (Sieber ex DC.) Benth., Acacia terminalis, Comesperma ericinum DC. (fl), Platysace linearifolia 
(Cav.) C.Norman, Pteridium esculentum subsp. esculentum, Caustis flexuosa R.Br., Poranthera microphylla Brongn. (fl), Haemodorum planifolium R.Br. (fl), Dampiera stricta (fl). Site visited 12 November 2009.

\section{Floral presentation and observation of individual flowers}

We recorded floral presentation in inflorescences of both species in situ. Flowers were examined with $3.5 \times$ Optivisors. To determine fragrance, fresh individual flowers were placed in individual, clean jars, with lids attached for 30-60 minutes. The lid was removed and the contents smelled at 15,30 and 60 minute intervals.

\section{Observation, collection, identification and measurement of insects}

We observed flowers of both species from 9 a.m. to noon and then from 2 p.m. to 5 p.m. Observation after sundown was discontinued after one two-hour session as no animals appeared to forage on these flowers. Insects were photographed foraging on both plant species. Specimens observed to forage on anthers of either species were netted and euthanised in separate jars containing fumes of ethyl acetate. These insects were washed of pollen (see below), pinned, labeled and measured. Killing jars were washed with diluted detergents and allowed to air dry overnight before reusing them. Four measurements were taken for each pinned and labeled specimen using digital calipers; length (from frons to terminus of abdomen), width (widest segment of insect abdomen), depth of the thorax and depth of abdomen. We included the last measurement (thickest part of the abdomen) as we noticed that jointed abdomens of native bees often appeared to clasp or curl over the clustered anthers, style and stigma of Symphionema montanum while foraging. Specimens were identified by Drs Michael Batley, David K. McAlpine, Chris Reid and Daniel Bickel (Australian Museum, Sydney) and deposited in the same museum.

\section{Pollen load analyses}

To identify and record pollen carried by foragers of each plant species, insect specimens were processed within 24 hours after capture. Each specimen was placed on a glass slide and bathed in 1-2 drops of ethyl acetate. The additional scopal (Colletidae, Halictidae) or corbicular (Apidae) loads were removed with a probe and added to the slide surface. Grains left on the slide following evaporation of the solvent were stained with Calberla's fluid (Ogden et al., 1974) and mounted with glass cover slips for light microscopy. All techniques for washing, staining, mounting, observing grains and co-referencing the label on the slide to the label under the pinned insect followed Bernhardt et al. (2014). As more than one insect was euthanised in the same jar, with separate jars for Isopogon anemonifolius and Symphionema montanum, pollen of a known species was considered present on a slide after $>25$ grains of that morphotype were counted. Therefore, pollen loads from each foraging insect were classified as one of the following: no pollen $(<25$ grains), pure loads $(>25$ grains of host flower only), mixed load ( $>25$ grains of host flower $+>25$ grains of at least one other coblooming species), and alien load ( $>25$ grains of other species but no grains of the host flower). While pollen grains of Symphionema montanum and Isopogon anemonifolius show morphological similarities (Milne \& Martin, 1998), they were segregated under 
$20 \times$ light microscopy by comparing relative sizes (big. vs little), exine patterns, and sculpturing of operculate wall pores.

\section{Statistical analyses}

The design of this study is to examine the contrast between the bee taxa visiting these two species with different modes of floral presentation. Therefore, for all comparisons we used a t-test with pooled variances. We tested for the assumptions of normality of data and homogeneity of variances, and both were met. All four body variables were recorded for each collected specimen. We estimated the mean, standard deviation, standard error of the mean, minimum and maximum values of each character. Bee size distribution was compared between the two plant species using a G-test. A quantile regression was used to determine the relationship between bee body size and number of pollen morphotypes using the package 'quanteg' (v. 5.35). All statistical analyses were performed in the R computational environment (v. 3.4.1; R Core Team, 2017).

\section{Results}

\section{Floral presentation}

Layered flower buds in dense, compact inflorescences of Isopogon anemonifolius (Fig. 1) open acropetally but in a helical pattern. Cream-yellowish flowers open when their buds are suberect to horizontal with the scape becoming increasingly nutant as they age. Dissection of flowers confirmed the absence of floral nectaries. The introrse, yellow-orange anthers dehisce in the bud through longitudinal slits, leaving pollen deposited on the subterminal part of the style that becomes the pollen presenter. The distal, free parts of the long tepals, with their attached anthers, reflex, exposing the elongated style, with its subterminal pollen presenter covered in pollen. No discernible fragrance was detected.

Inflorescences of Symphionema montanum (Fig. 1) are held erect to sub-erect or occasionally horizontal at anthesis. Dissection of fresh flowers confirmed the absence of floral nectar glands. Tepals appear waxy white-cream to the human eye with large yellow anthers clustering around the protruding stigma. Anthers have longitudinal sutures but their dehiscence is terminal and is interpreted as porose instead of porate (sensu Buchmann, 1983) as in some Hibbertia Andrews species (Bernhardt, 1996). This is contrary to previous descriptions (e.g. Telford, 1995) in which the anthers are described as showing typical longitudinal dehiscence. That may be the result of floral morphologists examining withered or pressed specimens as these anther sutures continue to separate towards their bases as they age and dry. The anthers encircle the style but do not extrude pollen onto it. There was no discernible fragrance.

\section{Forager diversity and behaviour}

Visitors to Isopogon anemonifolius were restricted to 44 native bees in two families (Apidae and Colletidae; Table 1, Fig. 2). The most commonly collected were females of Callomelitta antipodes. Bees observed and collected in situ on 9 \& 10 Nov 2009 

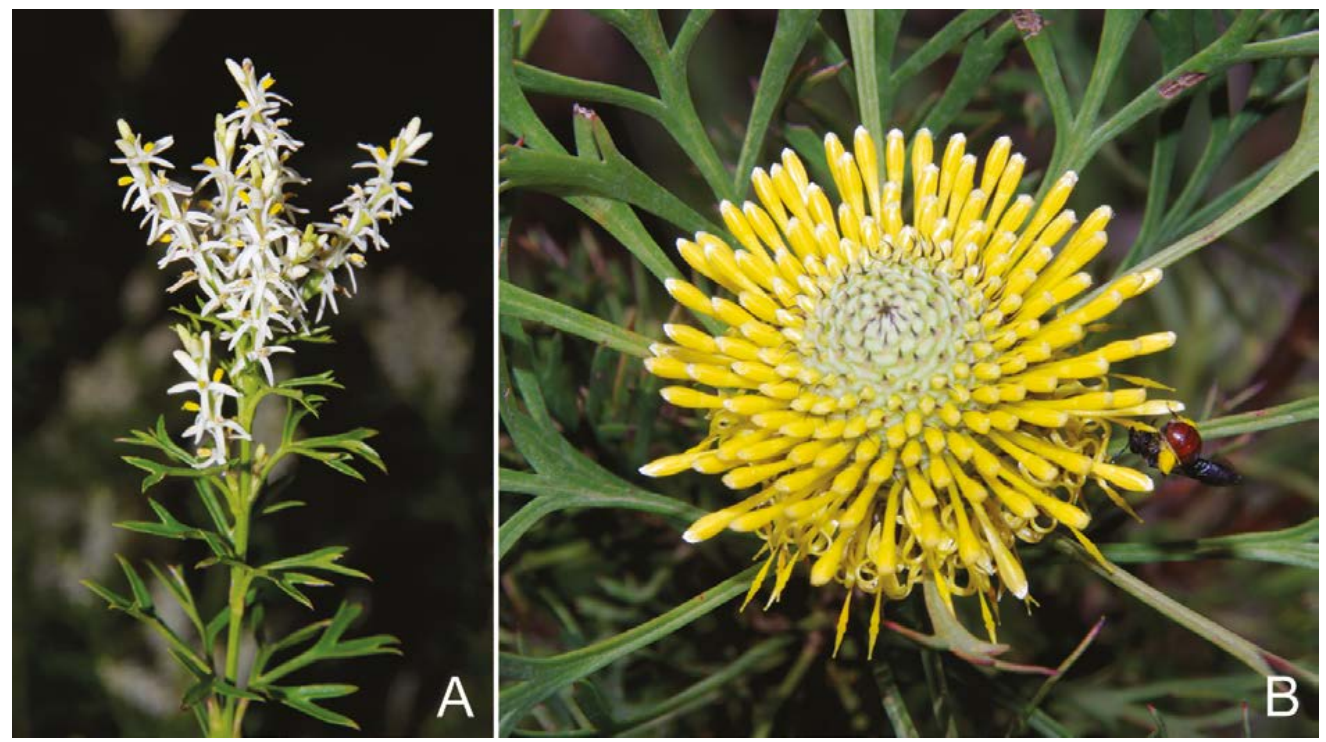

Fig. 1. A. Branching, spicate inflorescence of Symphionema montanum. B. Simple, capitate inflorescence of Isopogon anemonifolius. (Photos: P. Weston)

did not visit the flowers but perched on the inflorescence and were identified as males of Hylaeus littleri (Colletidae). These males may have used these shrubs as territorial markers (M. Batley, pers. comm.) and were the only male bees collected on this species (Table 1). Female bees in the genus Exoneura (Apidae) and Callomelitta antipodes (Colletidae) were also observed to visit some flowers in which the tepals were only partially opened and not fully reflexed. As the majority of flowers visited were nodding, with fully reflexed tepals, this required bees to forage upside down. We noted that Callomelitta antipodes and Leioproctus nigrofulvus foraged by using their mandibles to cling to the portion of the style protruding above the tepals. These bees then scraped the pollen presenter with their forelegs transferring pollen to the scopae on their hind legs using their middle pairs of legs.

Visitors to Symphionema montanum represented three insect Orders (Table 1) but buprestid beetles and syrphid flies in the genus Melangyna actually foraged on anthers less frequently than bees. Bees representing three families were the most common foragers. The weight of a bee often caused the flower to nod so the act of foraging was completed in an inverted position. The most common foragers were female bees in the short-tongue family Halictidae, represented by Homalictus holochorus and four Lasioglossum species. We noted that these bees landed or crawled to the apices of the cylinder of anthers. This required clasping or placing their abdomens on the protrusive stigma in each flower. The act of clasping lasted for several seconds suggesting buzzpollination but we did not hear the characteristic noise associated with buzz-pollination by larger species in the Apidae such as Bombus species (see Cardinal et al., 2018). 
Table 1. Pollen load analyses.

\section{POLLEN LOAD}

TAXON

$\begin{array}{ccc}\text { Pure Load } & \begin{array}{c}\text { Host Pollen } \\ + \text { Other } \\ \text { Spp. }\end{array} & \text { Other Spp. No Pollen }\end{array}$

\section{Symphionema montanum}

\section{Coleoptera}

Casitarina sp.

0

1

0

0

\section{Diptera}

Melangyna spp

12

1

Sapromyza sp.

0

2

7

0

0

Apoideae (Apidae)

Exoneura sp.

1

3

0

0

Colletidae

Leioproctus (Leioproctus) sp. nov.

2

0

0

0

Apoideae (Halictidae)

Homalictus holochorus

Lasioglossum callomelittinum

$\begin{array}{llll}2 & 0 & 0 & 0\end{array}$

L. clelandi

0

11

$0 \quad 0$

L. (Ctenonomia) $\mathrm{sp.}$

0

1

$0 \quad 0$

L. littleri

0

1

0

Grand Totals

1

4

$0 \quad 0$

Isopogon anemonifolius

Apidae

Exoneura sp.

3

2

0

\section{Colletidae}

\begin{tabular}{lcccc} 
Callomelitta antipodes & 2 & 30 & 0 & 0 \\
Hylaeus littleri & 0 & 0 & 0 & 1 \\
Leioproctus nigrofulvus & 3 & 1 & 0 & 0 \\
\hline Grand Totals & 8 & 34 & 1 & 1 \\
\hline
\end{tabular}




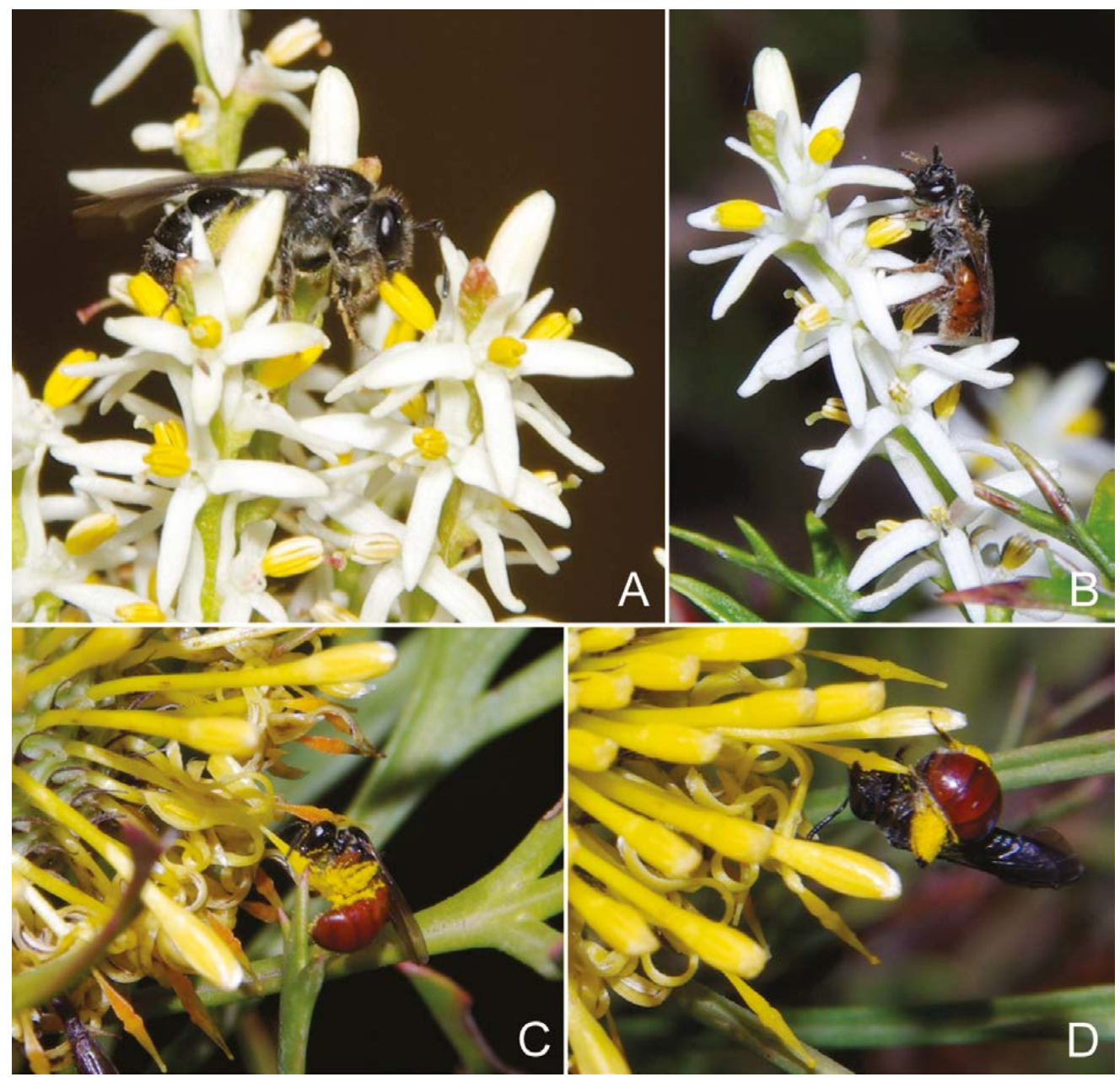

Fig. 2. A. Lasioglossum (subgenus Chilalictus) spp. visiting flowers of Symphionema montanum. B. Homalictus sp. visiting flowers of S. montanum. C. Exoneura sp. visiting flowers of Isopogon anemonifolius. Note the stigma at the tip of the pollen presenter contacting the pollen covered abdomen of the bee. D. Callomelitta antipodes visiting flowers of I. anemonifolius. Note the bee grasping the style below the pollen presenter with its mandibles. All photo identifications by Michael Batley. (Photos: P. Weston)

\section{Pollen Load Analyses}

Only eight bees carried pure loads of the pollen of Isopogon anemonifolius, while $36(>77 \%)$ of the total bees collected carried the host flower's pollen mixed with one to three morphotypes representing members of the co-blooming flora (Table 1). An average of $>2(2.89 \pm 1.34)$ recognisable pollen morphotypes were found on these insects. The dominant, most commonly caught forager, Calomelitta antipodes, carried an average of $<3$ recognisable pollen species $(2.17 \pm 0.61)$. The only bee carrying a total of four pollen morphotypes was a specimen of Callomelitta antipodes collected on 03/11/09 carrying the pollen of Isopogon anemonifolius, Hakea sp., mixed Myrtaceae 
and Symphionema montanum (Table 2). This specimen and an additional Callomelitta antipodes, collected on the same day, were the only bees in this study found to carry the pollen of both Isopogon anemonifolius and Symphionema montanum.

Only six out of 26 bees collected on Symphionema montanum carried pure loads of the pollen of this species in their scope or corbiculae, while $20(>79 \%)$ carried mixed loads (Table 1). Bees carrying pollen of Symphionema montanum mixed with grains of co-blooming species carried one to five additional morphotypes. An average of $<3$ $(2.89 \pm 1.34)$ pollen morphotypes were found on these insects. Lasioglossum species, the most commonly collected genus, carried $<4(3.4 \pm 1.28)$ recognisable morphotypes. The single specimen carrying 6 pollen morphotypes was a female of Lasioglossum callomelittinum collected on 2 November 2009 (Table 2). This included pollen of Symphionema montanum, Hakea sp., mixed Myrtaceae, papilionoid legume(s) and an unidentified, tetracolporate (eudicot) grain.

The number of pollen morphotypes carried in mixed loads differed significantly according to whether they were caught on Symphionema montanum or on Isopogon anemonifolius $(\mathrm{P}<0.0001)$. Visitors to Symphionema montanum averaged $3.4 \pm 0.7$ (mean $\pm \mathrm{SE}$ ) different morphotypes while visitors to Isopogon anemonifolius carried only $1.8 \pm 0.6$. Differences were driven mostly by Lasioglossum species visiting Symphionema montanum, and Callomelitta antipodes collected on Isopogon anemonifolius $(\mathrm{P}<0.0001$ in both contrasts $)$.

We tested the hypothesis that bee size influences pollen load diversity, given that pollen diversity can have a significant impact on plant reproductive output (Arceo-Gómez \& Ashman, 2011). Quantile regression (tau=0.75) of pollen load diversity against body size showed a significant positive relationship for both bees on both shrub species (Fig. 3). For bees on Isopogon (Fig. 4A) the slope of the line was 0.5195 ( \pm 0.2260), while for those on Symphionema (Fig. 4B) the slope was 0.7752 $( \pm 0.2033)$, and these were significantly different from each other $(\mathrm{t}=7.39, \mathrm{P}=0.014)$ with Symphionema bees having greater diversity of pollen load with increase in size than do bees from Isopogon.

\section{Bee Dimensions}

Bee dimension parameters (Table 3), comparing all bees collected on both species, were not significant. This comparative lack of statistically significant differences in sizes among the bee visitors is due, most likely, to the large variation in bee body sizes and the unequal bee collections taken on the two shrub species. However, we also compared the dominant foragers of each species: Callomelitta antipodes for Symphionema montanum vs all Lasioglossum species (Halictidae) for Isopogon anemonifolius. In this second analysis, there were significant differences in total body length (Fig. 3), with Lasioglossum species larger than Callomelitta antipodes $(\mathrm{P}=$ 0.0094). Thorax width was also significant, with Lasioglossum species wider than Callomelitta antipodes $(\mathrm{P}=0.0483)$, but abdomen depth was not.

We compared the overall bee size distribution for the total bee visitors for each plant species (Fig. 3). The size distribution of bee visitors to Symphionema was shifted significantly to the right as compared to that of Isopogon $(\mathrm{G}=17.7$, d.f. $=5, \mathrm{P}=$ 


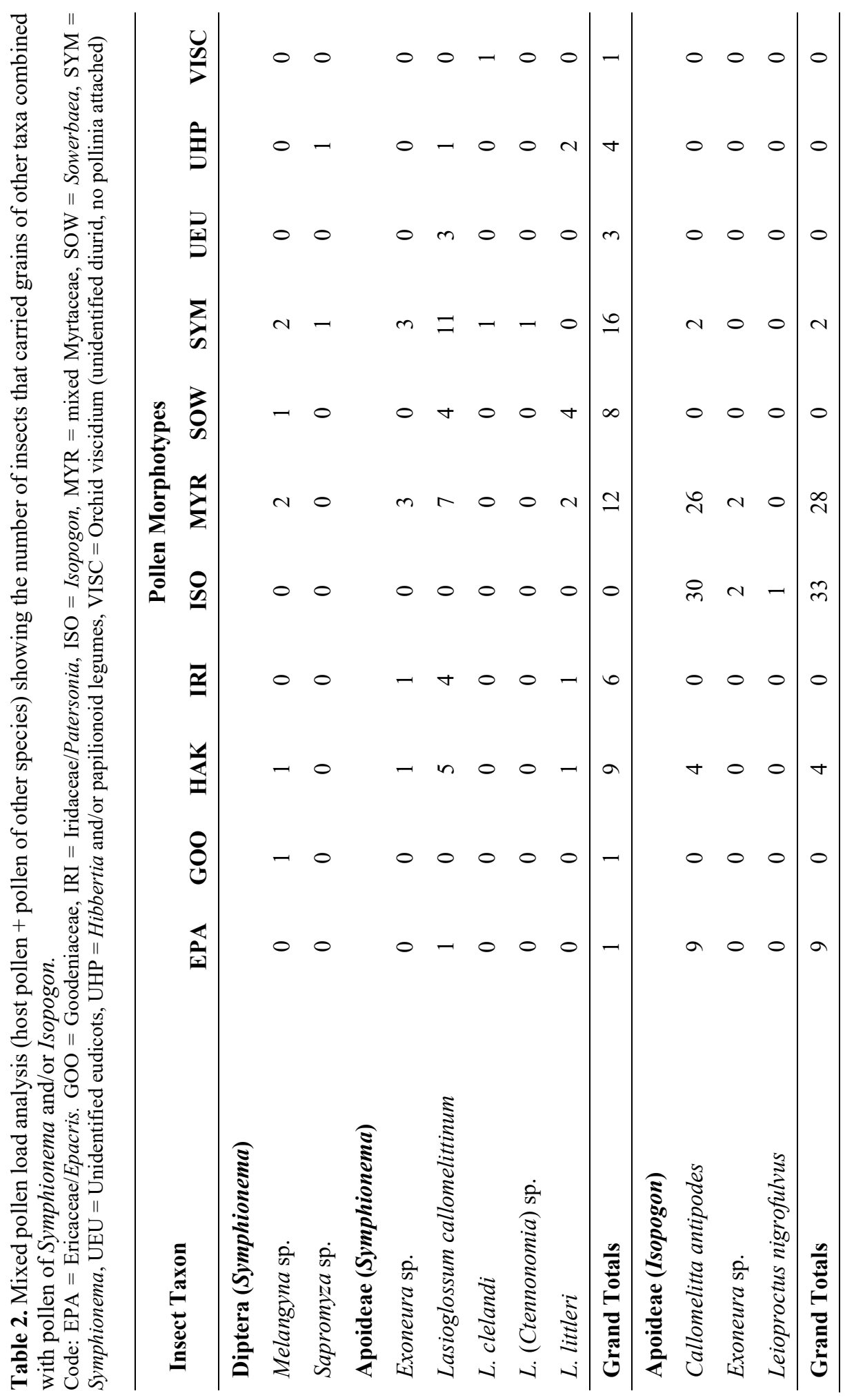




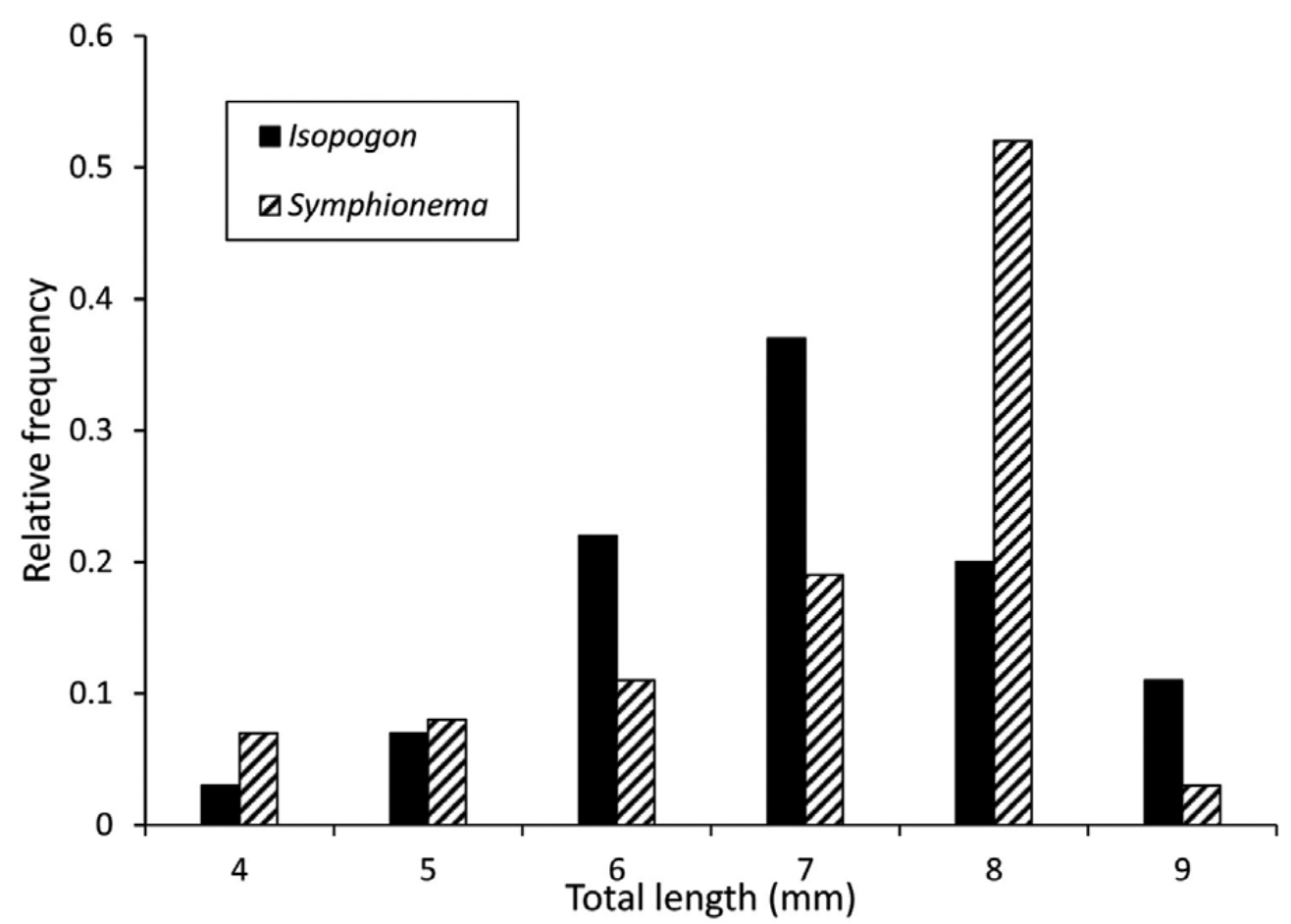

Fig. 3. Relative distribution of total bee length in Isopogon anemonifolius and Symphionema montanum. Distributions were significantly different from each other with $S$. montanum, in general, visited by larger bees than I. anemonifolius.

0.0232). More than $60 \%$ of bees collected on Symphionema are $8 \mathrm{~mm}$ in length or longer. In contrast, less than $25 \%$ of bees collected on Isopogon fit either of these size categories with $60 \%$ of Isopogon bees remaining at 6 and $7 \mathrm{~mm}$ intervals (Fig. 3).

\section{Discussion}

\section{Floral presentation}

Neither species produced a discernible odour but the colours of the tepals and anthers differed between Symphionema montanum and Isopogon anemonifolius. In the future, these much reflexed tepals and prominently exposed anthers of both species should be checked for UV patterns using digital techniques for matching the spectral sensitivity of bee photoreceptors (see Verhoeven et al., 2018). Floral presentation in Isopogon anemonifolius converges with some other insect-pollinated, woody, Australian plants that mass their flowers but do not secrete nectar. The most obvious similarity is with Petrophile R.Br. ex Knight species (Proteaceae), as shrubs in this genus have remarkably similar, cone-like inflorescences. Flowers of Petrophile species do not secrete nectar either, and show pollen presentation on their styles, but no detailed 

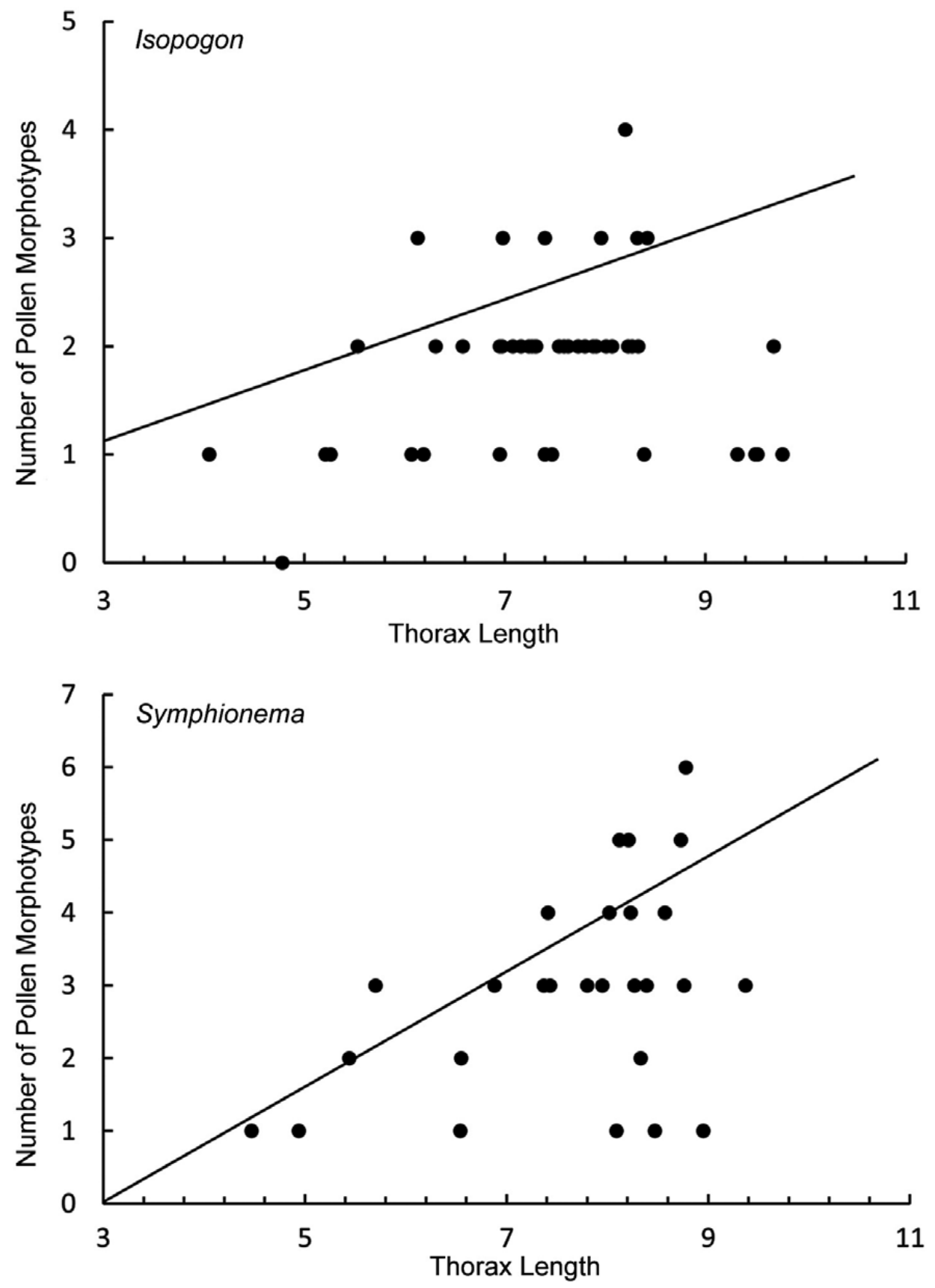

Fig. 4. Pollen morphotype species richness as a function of bees' thorax depth for Isopogon anemonifolius and Symphionema montanum. Quantile regression for both species were significant. 
Table 3. Bee species sample sizes and morphological dimensions - mean followed by (standard deviation).

\begin{tabular}{|c|c|c|c|c|c|}
\hline Isopogon & $\mathbf{N}$ & Total length & Total width & $\begin{array}{c}\text { Thorax } \\
\text { depth }\end{array}$ & $\begin{array}{c}\text { Abdomen } \\
\text { depth }\end{array}$ \\
\hline Callomelitta antipodes & 47 & $7.56(0.57)$ & $2.46(0.35)$ & $2.21(0.41)$ & $1.84(0.39)$ \\
\hline Exoneura sp. & 8 & $5.89(1.18)$ & $1.89(0.47)$ & $1.32(0.25)$ & $1.32(0.31)$ \\
\hline Hylaeus littleri & 2 & $5.49(1.0)$ & $1.32(0.55)$ & $1.15(0.47)$ & $1.08(0.69)$ \\
\hline Leioproctus nigrofulvus & 5 & $9.56(0.17)$ & $3.41(0.18)$ & $2.76(0.35)$ & $1.99(0.27)$ \\
\hline Total & 62 & $7.40(1.24)$ & $2.41(0.58)$ & $2.07(0.58)$ & $1.74(0.44)$ \\
\hline \multicolumn{6}{|l|}{ Symphionema } \\
\hline Exoneura sp. & 5 & $6.61(0.61)$ & $2.28(0.22)$ & $1.48(0.38)$ & $1.65(0.16)$ \\
\hline Homalictus holochorus & 2 & $4.71(0.33)$ & $1.68(0.09)$ & $1.23(0.02)$ & $1.05(0.19)$ \\
\hline Lasioglossum (Ctenomia) sp. & 1 & 5.44 & 1.79 & 1.27 & 1.13 \\
\hline L. callomelittinum & 12 & $8.38(0.42)$ & $2.70(0.24)$ & $2.22(0.38)$ & $2.09(0.39)$ \\
\hline L. clelandi & 1 & 7.80 & 2.57 & 1.71 & 1.93 \\
\hline L. littleri & 4 & $7.92(0.35)$ & $2.81(0.49)$ & $2.09(0.43)$ & $2.17(0.12)$ \\
\hline Leioproctus sp. nov. & 2 & $8.92(0.64)$ & $2.74(0.14)$ & $2.12(0.60)$ & $2.02(0.45)$ \\
\hline Total & 27 & $7.62(1.27)$ & $2.53(0.42)$ & $1.93(0.51)$ & $1.90(0.45)$ \\
\hline
\end{tabular}


studies of pollination in this genus have been published. Most insect-pollinated Acacia Mill. species also produce dense but smaller inflorescences. Their florets also lack nectar and most appear to be pollinated by native bees and syrphid flies (Bernhardt, 1989). We also note that most Hibbertia species in Australia have yellow flowers, some mass their flowers (Hibbertia sect. Pleurandra), never secrete nectar, and some have porose anthers (Bernhardt, 1984, 1996). We also suggest it may be time to reinterpret the function of anthers in Symphionema montanum. These organs did not appear to be particularly explosive (sensu Carolin, 1961; Ye et al., 2012) unless tapped hard with a probe or squeezed manually (Bernhardt \& Weston, unpublished). Their morphology seems closer to the oversized, inflated, porose/porate anthers associated with other buzz-pollinated flowers (Buchmann, 1983). This porose mode of dehiscence in Symphionema montanum may restrict some pollen thieves (but see below). While this was a short-term field study, we can conclude with reasonable confidence that the absence of floral and extra-floral nectar glands helps explain the absence of floral foragers belonging to the order Lepidoptera and of the many species of Australian nectar-drinking wasps (Bernhardt, 1987).

\section{Forager diversity and selective foraging behaviour}

Although anther presentation and dehiscence in Symphionema montanum appears to restrict pollen access to polylectic foragers it was visited by three more bee species than Isopogon anemonifolius. The terminal and porose anther openings of Symphionema montanum also appear to release or 'leak' enough pollen to attract syrphid flies. These flies may pick up waste grains left by bees or scavenge on drying anthers with separating sutures. While it may be easier for some bees to scrape pollen off the presenter of Isopogon anemonifolius we note that bees on Isopogon also had to forage upside down as the flowers nod at maturity.

In either case, collection of pollen from flowers that do not offer nectar means that foraging vectors face an immediate and continuous loss of chemical energy as they fly repeatedly to a species that is pollen rich but devoid of diluted sugars (Bernhardt, 1984, 1996). In particular, foraging on Symphionema montanum implies the additional effort of thoracic vibration and shaking. This would incur an even greater loss of energy. In fact, flowers that lack nectar and require anther sonication are common in temperate, sclerophyll woodlands in Australia, and this mode of pollen presentation is exploited by other distantly related lineages of eudicots and petaloid monocots. Some are pollinated, in part, or exclusively by halictid bees (Bernhardt, 1984, 1995, 1996; Houston \& Ladd, 2002; Driscoll, 2003; Johnson \& McQuillan, 2011; Ladd et al. 2019). Symphionema montanum may be the first example of a buzz-pollinated species described in the Australian Proteaceae but it is probably not the last considering floral diversity in the family and the similarity of its flowers to those of its sister species, $S$. paludosum $\mathrm{R} . \mathrm{Br}$.

While both species of shrubs shared infrequent visits from polylectic bees in the genera Exoneua (Apidae) and Leioproctus (Colletidae), the majority of foragers on Symphionema montanum belonged to the family Halictidae, while Isopogon anemonifolius was visited primarily by members of the Colletidae. This suggests 
a limited segregation of the resident pollinator guild based, in part, on floral presentation. Colletids appear to scrape Isopogon anemonifolius while halictids 'shake' Symphionema montanum. As these shrubs show overlapping distributions and flowering seasons in the Blue Mountains this may reduce competition among female bees foraging for pollen on flowers that do not secrete nectar. Ladd et al. (2019) noted recently that a variant of buzz-pollinated Tetratheca paynterae Alford was also pollinated primarily by Lasioglossum species, but they represented only a fraction of the total bee community within the Windarling Range in southern Western Australia.

However, polylectic foraging is common in many bee species that visit flowers offering pollen as their only reward (see above). By visiting co-blooming but nectar secreting species these females acquire calories and have the option of collecting pollen from a more diverse range of angiosperms in a landscape where pollen from different species varies in volume and nutritional value. This explains the repeated presence of pollen morphotypes belonging to nectariferous species in the families Epacridaceae, Fabaceae with papilionoid flowers, Myrtaceae and some co-blooming Proteaceae (subtribe Hakeinae) on the scopae and bodies of female bees collected on both of our shrub species. This also parallels previous analyses of pollen loads of bees collected on flowers of some other Australian taxa that only offer pollen (Bernhardt 1984, 1986, 1989, 1995). However, pollen morphotype analyses in this study also indicates that, when nectar-secreting flowers are abundant, the same female bee can find enough chemical energy to invest in foraging on flowers of more than one taxon that lack nectar but offer copious amounts of pollen (e.g. Hibbertia and Sowerbaea Sm.). This parallels previous analyses of pollen loads of bees collected on co-blooming but nectar-lacking inflorescences of Australian Acacia species (Bernhardt \& Walker, 1984; Bernhardt, 1989), and when flowers of Dianella caerulea var. assera R.J.F.Hend. share some bees with Hibbertia scandens (Willd.) Dryand. (Bernhardt, 1995).

\section{Does bee size matter?}

The average length of female bees collected in this study was slightly more than $7 \mathrm{~mm}$, with bee width about $2.5 \mathrm{~mm}$ for each set of specimens caught and measured on either shrub species. Therefore, it appears, at first, that bee dimensions play no obvious role in determining which bee visits which flower on either shrub. However, if we take a closer look we see that Symphionema montanum is visited consistently and primarily by halictid bees, while Callomelitta antipodes (Colletidae) is the dominant pollen vector of Isopogon anemonifolius in the Blue Mountains. Therefore, when we review our measurements, we note that Symphionema montanums attracts some bee taxa that are longer and wider than those that forage on Isopogon anemonifolius.

A more detailed inspection of bee size distribution showed that the proportion of larger-bodied bees visiting Symphionema montanum is greater than that for Isopogon anemonifolius (Fig. 3). Furthermore, larger-bodied bees are carrying greater pollen load diversity regardless of which plant species they are visiting (Fig. 4), but this relationship is stronger for Symphionema montanum (Fig. 4B). Therefore, attracting larger bees may result in greater heterospecific pollen deposition. The specific behaviours that pollinators must carry out in order to harvest the pollen will also 
affect the frequencies of heterospecific pollen deposition. Based on past research we speculate that, as some native sonicators are also polylectic foragers, they may be more likely to visit a wider range of co-blooming species. As these bees sonicate the flowers of some species, but scrape the anthers of other taxa, they could transport more diverse pollen loads compared to some bees that are also polylectic but only scrape anthers (Bernhardt \& Montalvo, 1979; Bernhardt, 1984, 1986, 1995). We fully acknowledge, though, that our data in this study did not allow for sufficient replication to test for these effects and interactions.

At the intraspecific level it is well understood that the larger the bee the greater the sheer volume of pollen it carries (Ramalho et al., 1998; Leonhardt et al., 2007) but what of the interspecific level? Larger, polylectic bees should also carry more diverse pollen loads acquired during the same foraging bouts (Peat et al., 2005; Beil et al., 2008). Unfortunately, our work covers only one segment of a single flowering season, but results of our quantile regression suggest that, in some seasons and habitats, a minimally larger bee may carry the pollen of more co-blooming plants than smaller specimens.

A second interpretation should be considered based, instead, on bee phylogeny, demography and phenology. We speculate that, in some Australian habitats, at certain times during the flowering season, some Lasioglossum species may be more likely to visit more flowering species compared to some female colletids in the genera Callomelitta (Knox et al., 1985) and Leioproctus (Bernhardt, 1984, 1986, 1989; Bernhardt \& Walker, 1984; Bernhardt \& Weston, 1996). Unfortunately, this and previous studies (see above) represent bee collections far too small to test such a correlation between the foraging bouts of halictid. vs colletid bees. It requires years of monitoring and sampling. Therefore, we refer the reader to the work of Dr Michael Batley of the Australian National Museum who records the genera of Australian plants on which he collects each foraging bee. His collections of Callomelitta antipodes show they may visit flowers belonging to at least ten genera. Leioproctus nigrofulvus was collected on seven, with nine for Lasioglossum calomelittinum and 13 for Lasioglossum clelandi (https://figshare.com/projects/Flower-visiting_records for_Australian_native_bees/55847).

Those interested in additional comparisons regarding foraging preferences based on collections of Lasioglossum species vs Leioproctus species and Callomelitta antipodes on the Mediterranean flora of Western Australia should consult Houston (2000). Obviously, far more work needs to be done on insect-pollination in the Australian Proteaceae and their relative positions within pollination networks.

DEDICATION AND ACKNOWLEDGEMENTS. This paper is dedicated to our colleague Professor David Mabberley, with whom one of us (P.H.W.) has worked closely on problems in the families Rutaceae and Proteaceae. All of us have benefitted greatly from the wealth of information provided in various editions of Mabberley's Plant-book. The topics addressed in our research also converge with Professor Mabberley's contributions to knowledge of the flora of Australia, and his books and papers on the life and work of Robert Brown and Ferdinand Bauer. 
This research was conducted under a scientific research license issued to the Royal Botanic Gardens and Domain Trust by the New South Wales National Parks and Wildlife Service (NPWS). We are grateful to the staff of the Blue Mountains Heritage Centre at Govetts Leap for facilitating this work. We thank Rob Smith, Curator-Manager of the Blue Mountains Botanic Garden Mount Tomah in 2009, for providing accommodation at the Garden while we worked at our field sites in the Blue Mountains. Michael Batley (Australian Museum, Sydney) kindly provided helpful comments on earlier drafts of the manuscript and we thank the anonymous referees for their valuable comments and criticism.

\section{References}

Arceo-Gómez, G. \& Ashman, T.L. (2011). Heterospecific pollen deposition: does diversity alter the consequences? New Phytol. 192: 738-746.

Beil, M., Horn, H. \& Schwabe, A. (2008). Analysis of pollen loads in a wild bee community (Hymenoptera: Apidae) - a method for elucidating habitat use and foraging distances. Apidologie 39: 456-467.

Bernhardt, P. (1984). The pollination biology of Hibbertia stricta (Dilleniaceae). Plant Syst. Evol. 147: 266-277.

Bernhardt, P. (1986). Bee-pollination of Hibbertia fasciculata (Dilleniaceae). Plant Syst. Evol. 152: 231-241.

Bernhardt, P. (1987). A comparison of the diversity, density and foraging behaviour of bees and wasps on Australian Acacia. Ann. Missouri Bot. Gard. 74: 42-50.

Bernhardt, P. (1989). The floral ecology of Australian Acacia. In: Stirton, C.H. \& Zarucchi, J.L. (eds) Advances in legume biology, pp. 127-155. St. Louis, MO: Monographs in Systematic Botany from the Missouri Botanical Garden.

Bernhardt, P. (1995). The floral ecology of Dianella caerulea var. assera (Phormiaceae). Cunninghamia 4: 1-17.

Bernhardt, P. (1996). Anther adaptations for animal pollination. In: D’Arcy, W. \& Keating, R. (eds) The Biology of Anthers, pp. 192-220. New York, NY: Cambridge University Press.

Bernhardt, P. \& Montalvo, E.A. (1979). The pollination of Echeandia macrocarpa (Liliaceae). Brittonia 31: 64-71.

Bernhardt, P. \& Walker, K. (1984). Bee foraging on three sympatric species of Australian Acacia. Int. J. Entomol. 26: 322-330.

Bernhardt, P. \& Weston, P. (1996). The pollination ecology of Persoonia (Proteaceae) in eastern Australia. Telopea 6: 775-803.

Bernhardt, P., Edens-Meier, R., Westhus, E. \& Vance, N. (2014). Bee-mediated pollen transfer in two populations of Cypripedium montanum Douglas ex Lindley. J. Pollinat. Ecol. 13: $188-202$.

Blomberry, A.M. \& Maloney, B. (1992). The Proteaceae of the Sydney region. Kenthurst, New South Wales: Kangaroo Press.

Buchmann, S.L. (1983). Buzz pollination in angiosperms. In: Jones C.E. \& Little R.J. (eds) Handbook of experimental pollination biology, pp. 73-113. New York, NY: Van Nostrand Reinhold.

Cardinal, S., Buchmann, S.L. \& Russell, A.L. (2018). The evolution of floral sonication, a pollen foraging behavior used by bees (Anthophilia). Evolution 72: 590-600.

Carolin, C. (1961). Pollination of the Proteaceae. Austral. Mus. Mag. 13: 371-374. 
Citerne, H.L., Reyes, E., Le Guilloux, M., Delannoy, E., Simonnet, F., Sauquet, H., Weston, P.H., Nadot, S. \& Damerval, C. (2017). Characterization of CYCLOIDEA-like genes in Proteaceae, a basal eudicot family with multiple shifts in floral symmetry. Ann. Bot. (Oxford) 119: 367-378.

Collins, B.G. \& Rebelo, T. (1987). Pollination ecology of the Proteaceae in Australia and southern Africa. Austral. J. Ecol. 12: 387-421.

Driscoll, C. (2003). Pollination ecology of Tetratheca juncea (Tremandraceae): finding the pollinators. Cunninghamia 8: 133-140.

Faegri, K. \& van der Pijl, L. (1979). The principles of pollination ecology. 3rd ed. Oxford: Pergamon Press.

Harden, G.J. (2002a). Symphionema. In: Harden, G. (ed.) Flora of New South Wales, vol. 2, 2nd ed., p. 20. Kensington, N.S.W.: New South Wales University Press.

Harden, G.J. (2002a). Isopogon. In: Harden, G. (ed.), Flora of New South Wales, vol. 2, 2nd ed., pp. 21-22. Kensington, N.S.W.: New South Wales University Press.

Hattingh, V. \& Giliomee, J.H. (1989). Pollination of certain Leucadendron species (Proteaceae). S. African J. Bot. 4: 387-393.

Hawkeswood, T.J. (2007). Pollination of Conospermum taxifolium R.Br. (Proteaceaeae) by jewel beetles (Coleoptera: Buprestidae) in north-eastern New South Wales, Australia. Calodema Supplementary Paper No. 26: 1-4.

Heard, T.A. (1994). Behaviour and pollinator efficiency of stingless bees and honey bees on macadamia flowers. J. Apic. Res. 33: 191-198.

Houston, T.F. (1989). Leioproctus bees associated with Western Australian smoke bushes (Conospermum spp.) and their adaptations for foraging and concealment. Rec. West. Austral. Mus. 14: 275-292.

Houston, T.F. (2000). Native bees on wildflowers in Western Australia. Special Publication No. 2 of the Western Australian Insect Study Society Inc. Perth: Western Australian Museum.

Houston T.F. \& Ladd, P.G. (2002). Buzz pollination in the Epacridaceae. Austral. J. Bot. 50: 83-891.

Johnson, K.A. \& McQuillan, P.B. (2011). Comparative floral presentation and bee-pollination in two Sprengelia species (Ericaceae). Cunninghamia 12: 45-51.

Johnson, L.A.S. \& Briggs, B.G. (1975). On the Proteaceae: The evolution and classification of a southern family. Bot. J. Linn. Soc. 70: 83-182.

Johnson, S.D., Newman, E. \& Anderson, B. (2012). Preliminary observations of insect pollination in Protea punctata (Proteaceae). S. African J. Bot. 83: 63-67.

Knox, R.B., Kenrick, J., Bernhardt, P., Martinson, R., Beresford, G., Baker, I. \& Baker, H.G. (1985). Extra-floral nectaries as adaptations for bird pollination in Acacia terminalis. Amer. J. Bot. 72: 1185-1196.

Ladd, P.G., Yates, C.J., Dillon, R. \& Palmer, R. (2019). Pollination ecology of Tetratheca species from isolated, arid habitats (Banded Iron Formations) in Western Australia. Austral. J. Bot. 67: 248-255.

Leonhardt, S.D., Dworschak, K., Eltz, T. \& Bluthren, N. (2007). Foraging loads of stingless bees and utilization of stored nectar for pollen harvesting. Apidologie 38: 124-135.

Low, T. (2016). Where song began. New Haven, Connecticut: Yale University Press.

Mast, A.R., Milton, E.F., Jones, E.H., Barker, R.M., Barker, W.R. \& Weston, P.H. (2012). Time-calibrated phylogeny of the woody Australian genus Hakea (Proteaceae) supports multiple origins of insect-pollination among bird-pollinated ancestors. Amer. J. Bot. 99: 472-487. 
Milne, L. \& Martin, A.R.H. (1998). Conospermeae (Proteoideae) pollen morphology and its phylogenetic implications. Austral. Syst. Bot. 11: 503-552.

Ogden, E.C., Raynor, G.S., Hayers, J.V. \& Lewis, D.M. (1974). Manual for sampling airborne pollen. New York: Hafner Press..

Peat, J., Tucker, J. \& Coulson, D. (2005). Does intraspecific size variation in bumblebees allow colonies to efficiently exploit different flowers? Ecol. Entomol. 30: 1-6.

R Core Team (2017). $R$ : a language and environment for statistical computing. Vienna, Austria: R Foundation for Statistical Computing. https://www.R-project.org/.

Ramsey, M.W. (1988). Differences in pollinator effectiveness of birds and insects visiting Banksia menziesii (Proteaceae). Oecologia 1: 119-124.

Rao, C.V. (1971). Proteaceae. Rafi Marg, New Delhi, India: Council of Scientific and Industrial Research.

Ramalho, M., Imperatriz-Fonesca, V.L. \& Giannini, T.C. (1998). Within-colony size variation of foragers and pollen load capacity in the stingless bee Melipona quadrifasciata anthidiotes Lepeltier (Apidae, Hymenoptera). Apidologie 29: 221-228.

Reyes, E., Sauquet, H. \& Nadot, S. (2016). Perianth symmetry changed at least 199 times in angiosperm evolution. Taxon 65: 945-964.

Steenhuisen, S.L., Raguso, R.A. \& Johnston, S.D. (2012). Floral scent in bird- and beetlepollinated Protea species (Proteaceae): chemistry emission rates and function. Phytochemistry 84: 78-87.

Telford, I.R.H. (1995). Symphionema. Flora of Australia 16: 133-135.

Tremblay, R.L., Ackerman, J.D., Zimmerman, J.K. \& Calvo, R.N. (2004). Variation in sexual reproduction in orchids and its evolutionary consequences: a spasmodic journey to diversification. Biol. J. Linn. Soc. 84: 1-54.

Vaughton, G. (1996). Pollination disruption by European honeybees in the Australian birdpollinated shrub Grevillea barklyana (Proteaceae). Plant Syst. Evol. 200: 89-100.

Verhoeven, C., Ren, Z-X. \& Lunau, K. (2018). False-colour photography: a novel digital approach to visualize the bee view of flowers. J. Pollinat. Ecol. 23: 102-118.

Vithanage, H.I.M.V. \& Ironside, D.A. (1986). The insect pollinators of macadamia and their relative importance. J. Austral. Inst. Agr. Sci. 52: 155-160.

Welsford, M.R., Hobbhahn, N., Midgley, J.J. \& Johnson, S.D. (2016). Floral trait evolution associated with shifts between insect and wind pollination in the dioecious genus Leucadendron (Proteaceae). Evolution 70: 126-139.

Weston, P.H. (2007). Proteaceae. In: K. Kubitzki (ed.) Families and genera of vascular plants, vol. IX, pp. 364-404. Berlin: Springer.

Weston, P.H. (2014). What has molecular systematics contributed to our knowledge of the Proteaceae? In: P. Besse (ed.) Molecular plant taxonomy: methods and protocols, pp. 365-397. Methods in Molecular Biology, vol. 1115. New York: Springer.

Williams, G. \& Adam, P. (2010). The flowering of Australia's rainforests: a plant and pollination miscellany. CSIRO Publishing, Melbourne.

Ye, Q., Bunn, E. \& Dixon, K. (2012). A ballistic pollen dispersal system influences pollination success and fruit-set pattern in pollinator-excluded environments for the endangered species Synaphea stenoloba (Proteaceae). Bot. J. Linn. Soc. 170: 59-68. 